\title{
Reactions, Coalescence of Reduced Iron Particles, and Liberation of Carbon Particles in Carbon Composite Iron Ore Pellets
}

\author{
Yoshiaki IGUCHI and Satoshi ENDO'1) \\ Nagoya Institute of Technology, Materials Science and Engineering, Gokiso-cho, Showa-ku, Nagoya 466-8555 Japan. \\ 1) Former Graduate Student, Nagoya Institute of Technology, Gokiso-cho, Showa-ku, Nagoya 466-8555 Japan. Now at Toyoda \\ Machine Works, Ltd., 1, Asahi-cho 1 chome, Kariya, Aichi 448-8652 Japan.
}

( Received on April 22, 2004; accepted in final form on August 23, 2004)

\begin{abstract}
Reactions in carbonaceous material composite iron ore pellets of $18 \mathrm{~mm}$ heated at elevated temperatures were studied. The overall reduction rate is controlled by a complex combination of direct reactions and indirect reactions and never by gasification reaction. The final reduction of iron oxide is controlled by carburized carbon. The carburization of the reduced iron is mainly progressed by the direct carburization reaction, $\mathrm{C}(\mathrm{s})=[\mathrm{C}]$. As the carbon content approaches to the solidus line of the phase diagram of Fe-C system, the reduced iron particles are gradually forced to coalesce to grow in much larger particles. The coalescing rate is increased with temperature. Its driving force is the large surface energy of reduced iron due to its large specific surface area. Due to the coalescence, the particles of carbon are apt to lose the contact state with the reduced iron particles and to lose the ability to carburize the reduced iron. Therefore, the carburization exceeding the solidus line can be severely depressed. Consequently, the carburization up to the solidus line can be achieved at relatively lower temperatures, i.e. $1200-1250^{\circ} \mathrm{C}$. As a result, the carbon content of reduced iron decreases with increasing temperature. Since the coal char has a very poor ability to directly carburize reduced iron, the carbon contents of reduced iron were very low and increased with increasing temperature. Graphite and coke possess the strongest and the intermediate carburizing abilities, respectively. And the carbon contents of the shell part and core part of reduced iron decreases with increasing temperature.
\end{abstract}

KEY WORDS: iron ore; carbonaceous material; composite pellet; reduced iron; direct carburization; carbon content; solidus line; coalescence; detachment; free carbon.

\section{Introduction}

Recently, new ironmaking processes ${ }^{1-5)}$ of high efficiency and high productivity have been developed by heating powder mixture of iron ore with carbonaceous material. Also, carbon composite iron ore hot briquette has been tested as a superior burden to blast furnace. ${ }^{6,7)}$ In the mixture heated at elevated temperatures, a number of reactions progress very fast, which are consecutive reactions and parallel reactions, strongly endothermic reactions and weakly exothermic reactions, and solid-solid reactions and solid-gas reactions. And the individual reactions have very intimate interactions with the other reactions. Due to the complexity, it is very difficult to understand the reactions inside the mixture to a required level to develop the processes of high efficiency and high productivity. The authors are confident that the key to achieve the objective is to get an enough level of knowledge about the carburization of reduced iron; e.g. the mechanism of carburization, the level of the carburization, the influence of the kind and size range of carbonaceous materials, influence of gasification reaction and so on. In the previous study, ${ }^{8)}$ the authors have succeeded in measuring the content of carbon dissolved in reduced iron by removing attached particles of carbonaceous materials to reduced iron particles by repeatedly cleaning the reduced iron particles in fresh ethanol under ultrasonic vibration. In this study, deepening the understanding about the carburization of reduced iron in the composite pellets heated at elevated temperatures is tried as far as possible.

\section{Experimental}

In the previous study, ${ }^{8)}$ iron ore-carbon composite pellets were prepared in various combinations of two kinds of iron ore, i.e. Samarco ore and Mt. Newman ore, and three kinds of carbonaceous materials, i.e. coal char from lignite, metallurgical coke and reagent graphite. The chemical compositions of the materials are shown in Table 1. The size range of the materials was under $45 \mu \mathrm{m}$ excluding the case where the coal char particles of size range from 53 to $106 \mu \mathrm{m}$ were used to investigate the influence of size of the carbonaceous material on the reactions. In mixing the iron ores with the carbonaceous materials, the molar amount of reducible oxygen in the ore was made equal to the molar amount of fixed carbon in the carbonaceous material. To the mixtures, one mass percent of Bentonite as binder was added and fully mixed. Then, the mixtures formed into pellets of $18 \mathrm{~mm}$ in diameter on the inside wall of a rotating tire. The single composite pellets were heated in nitrogen flow of $1 \times 10^{-3} \mathrm{Nm}^{3} / \mathrm{min}$ at temperatures from 1150 to 
Table 1. Chemical compositions of iron ore and carbonaceous materials used in this study.

\begin{tabular}{|c|c|c|c|c|c|c|c|}
\hline \multicolumn{8}{|c|}{ (a) Samarco ore (mass\%) } \\
\hline T.Fe & $\mathrm{SiO}_{2}$ & $\mathrm{Al}_{2} \mathrm{O}_{3}$ & $\mathrm{P}$ & $\mathrm{S}$ & $\mathrm{K} 2 \mathrm{O}$ & $\mathrm{FeO}$ & $\mathrm{CaO}$ \\
\hline 66.74 & 1.76 & 0.35 & 0.051 & 0.005 & $<0.01$ & 0.68 & 0.06 \\
\hline \multicolumn{8}{|c|}{ (b) Coal char (mass\%) } \\
\hline Ash & \multicolumn{2}{|c|}{\begin{tabular}{|l|} 
Volatile matter \\
\end{tabular}} & \multicolumn{2}{|c|}{ Fixed carbon } & & & \\
\hline 2.8 & \multicolumn{2}{|c|}{6.17} & \multicolumn{2}{|c|}{91.04} & & & \\
\hline \multicolumn{8}{|c|}{ (c) Graphaite (mass\%) } \\
\hline Water & \begin{tabular}{|l|} 
Ash \\
\end{tabular} & Purity & & & & & \\
\hline$<0.50$ & $<0.05$ & $>99.50$ & & & & & \\
\hline \multicolumn{8}{|c|}{ (d) Coke (mass\%) } \\
\hline Ash & \multicolumn{2}{|c|}{ Volatile matter } & sulfer & $\mathrm{C}$ & $\mathrm{H}$ & $\mathrm{N}$ & $\mathrm{O}$ \\
\hline 11.9 & \multicolumn{2}{|c|}{06} & 0.46 & 86.33 & 0.14 & 0.8 & 0.37 \\
\hline
\end{tabular}

(e) Bentonite (mass\%)

\begin{tabular}{|r|c|c|c|c|c|c|}
\hline $\mathrm{SiO}_{2}$ & $\mathrm{Al}_{2} \mathrm{O}_{3}$ & $\mathrm{Fe}_{2} \mathrm{O}_{3}$ & $\mathrm{CaO}$ & $\mathrm{MgO}$ & $\mathrm{K}_{2} \mathrm{O}$ & $\mathrm{Na}_{2} \mathrm{O}$ \\
\hline 67.52 & 12.97 & 2.97 & 3.15 & 2.04 & 1.14 & 2.43 \\
\hline
\end{tabular}

\begin{tabular}{|l|l|l|l|l|l|l|}
\hline 67.52 & 12.97 & 2.97 & 3.15 & 2.04 & 1.14 & 2.43 \\
\hline
\end{tabular}

(f) Mt.Newman ore (mass\%)

\begin{tabular}{|c|c|c|c|}
\hline T.Fe & $\mathrm{SiO}_{2}$ & $\mathrm{Al}_{2} \mathrm{O}_{3}$ & $\mathrm{CaO}$ \\
\hline 63.3 & 4.1 & 2.4 & 0.05 \\
\hline
\end{tabular}

$1380^{\circ} \mathrm{C}$ by descending in $180 \mathrm{~s}$ from the top position of the reaction tube to the hot zone, and retained there until the reactions in the pellet finished, namely until the content of $\mathrm{CO}$ in the outlet gas became less than the error level of infrared gas analyzer. The heating times at 1150,1200 , $1250,1300,1350$ and $1380^{\circ} \mathrm{C}$ were $17,15,13,11,11$ and $10 \mathrm{~min}$ including the $3 \mathrm{~min}$ for heating up, respectively. Then, the reaction finished pellets were pulled up from the hot zone to the top position of the reaction tube in $3 \mathrm{~min}$ and cooled in $\mathrm{N}_{2}$ atmosphere. Then, the individual reacted pellets were cut into two hemispheres, separated into a shell part and a core part by picking the core from one of the hemispheres by a picking tool. If the core part could not be picked from the shell, the whole part was called as the shell part without the corresponding core part. Then, each part was pulverized in an alumina mortar and the powder was repeatedly cleaned in fresh ethanol under ultrasonic vibration to remove the attached particles of carbonaceous materials. The pulverized reduced iron of the shell part and the core part were analyzed for carbon by the combustion method. Thus, the average content of carbon dissolved in reduced iron was measured. Some reacted composite pellets were chemically analyzed to measure the contents of the metallic iron and remained FeO. Also, some hemispheres were mounted in resin and the morphology of the cross sections after etching with picric acid ethanol solution was observed to know rough carbon content of the reduced iron and the coalescence of reduced iron particles.

The curves of the fractional reduction of the iron ore and the fractional gasification of the coal char was calculated from the composition and flow rate of the outlet gas from the reaction tube, which composition was continuously measured by infrared gas analyzer. The flowing-out rate of the reducible oxygen, $F_{\mathrm{O}}[\operatorname{mol}(\mathrm{O}) / \mathrm{s}]$, and the flowing-out rate of the gasified carbon, $F_{\mathrm{C}}[\operatorname{mol}(\mathrm{C}) / \mathrm{s}]$, were calculated by Eqs. (1) and (2), respectively;

$$
\begin{gathered}
F_{\mathrm{O}}=\left[\left(\% \mathrm{CO}+2 \% \mathrm{CO}_{2}\right) /\left(100-\% \mathrm{CO}-\% \mathrm{CO}_{2}\right)\right] F_{\mathrm{N}_{2}} \\
F_{\mathrm{C}}=\left[\left(\% \mathrm{CO}+\% \mathrm{CO}_{2}\right) /\left(100-\% \mathrm{CO}-\% \mathrm{CO}_{2}\right)\right] F_{\mathrm{N}_{2}}
\end{gathered}
$$

In the equations, $\% \mathrm{CO}$ and $\% \mathrm{CO}_{2}$ are the percentages of $\mathrm{CO}$ and $\mathrm{CO}_{2}$ in the outlet gas, respectively. In the calculation, the percentage of $\mathrm{N}_{2}$ was approximated as $\% \mathrm{~N}_{2}=$ $100-\% \mathrm{CO}-\% \mathrm{CO}_{2}$ neglecting the contents of $\mathrm{H}_{2}$ and $\mathrm{H}_{2} \mathrm{O}$ in the outlet gas. $F_{\mathrm{N}_{2}}$ is the flow rate of $\mathrm{N}_{2}[\mathrm{~mol} / \mathrm{s}]$. The fractional reduction and fractional gasification were calculated by Eqs. (3) and (4), respectively.

$$
\begin{aligned}
& \text { Fractional reduction }=\int_{0}^{t} F_{\mathrm{O}} d t /[\text { initial mol }(\mathrm{O})] \ldots . \\
& \text { Fractional gasification }=\int_{0}^{t} F_{\mathrm{O}} d t /[\text { initial } \operatorname{mol}(\mathrm{C})] \ldots
\end{aligned}
$$

The terms of [initial mol(O)] and [initial mol(C)] are the total molar amount of reducible oxygen and fixed carbon in the single composite pellet used in the experiment, respectively. $t$ is the reaction time [s].

\section{Experimental Results Relevant to the Carburization of Reduced Iron}

\subsection{Reduction Curves and Gasification Curves Calcu- lated from Composition of Outlet Gas}

The reduction degree curves and gasification degree curves at $1250^{\circ} \mathrm{C}$ for the composite pellets of some combinations between Samarco ore or Mt. Newman ore and the coal char, coke or graphite, which curves were calculated by using Eqs. (3) and (4), are shown in Figs. 1(a) and 1(b). Figure 1(c) is an enlarged figure of the final stage of Fig.1 (a). The vertical axes of the Figs. 1(a) and 1(c), and Fig. (b) are the reduction degree relative to the initial amount of the reducible oxygen and the gasification degree relative to the initial amount of the fixed carbon, respectively. The reactions reach a state not evolving any $\mathrm{CO}$ within about $12 \mathrm{~min}$ at $1250^{\circ} \mathrm{C}$ and within $10 \mathrm{~min}$ at $1300^{\circ} \mathrm{C}$ or more. Since $\mathrm{CO}_{2}$ was detected in spite of much less amount than $\mathrm{CO}$, some carbon should remain in the reacted pellets taking into account the mixing ratio of $\mathrm{mol}(\mathrm{O}) / \mathrm{mol}(\mathrm{C})=1$. But the curves reached the final gasification degree greater than $102 \%$ with graphite and more than around $90 \%$ except the $25 \%$ coal char bearing composite pellet. The final reduction degrees of the curves, which all exceeded $100 \%$ and some curves approached even $120 \%$, may be attributed to some amount of water remained even after drying at $105^{\circ} \mathrm{C}$ for more than a half day, which water was added to in the pellet-making process. Especially, the coal char seems to absorb much more amount of water than the others. The reactions were identified to have finished when neither $\mathrm{CO}$ nor $\mathrm{CO}_{2}$ became detected in the outlet gas. Because of nitrogen atmosphere, the reduction reactions and the gasification reaction are to finish at the same time.

\subsection{Coalescence of Reduced Iron Particles in the Composite Pellets Heated at Elevated Tempera- tures}

Microphotographs of the cross sections of Samarco ore-coke composite pellets of $18 \mathrm{~mm}$ in diameter when the reactions just finished at $1200,1250,1300$ and $1350^{\circ} \mathrm{C}$ are shown in Figs. 2(a)-2(d), respectively. At $1200^{\circ} \mathrm{C}$, the cross section is almost homogeneous and neither the shell 

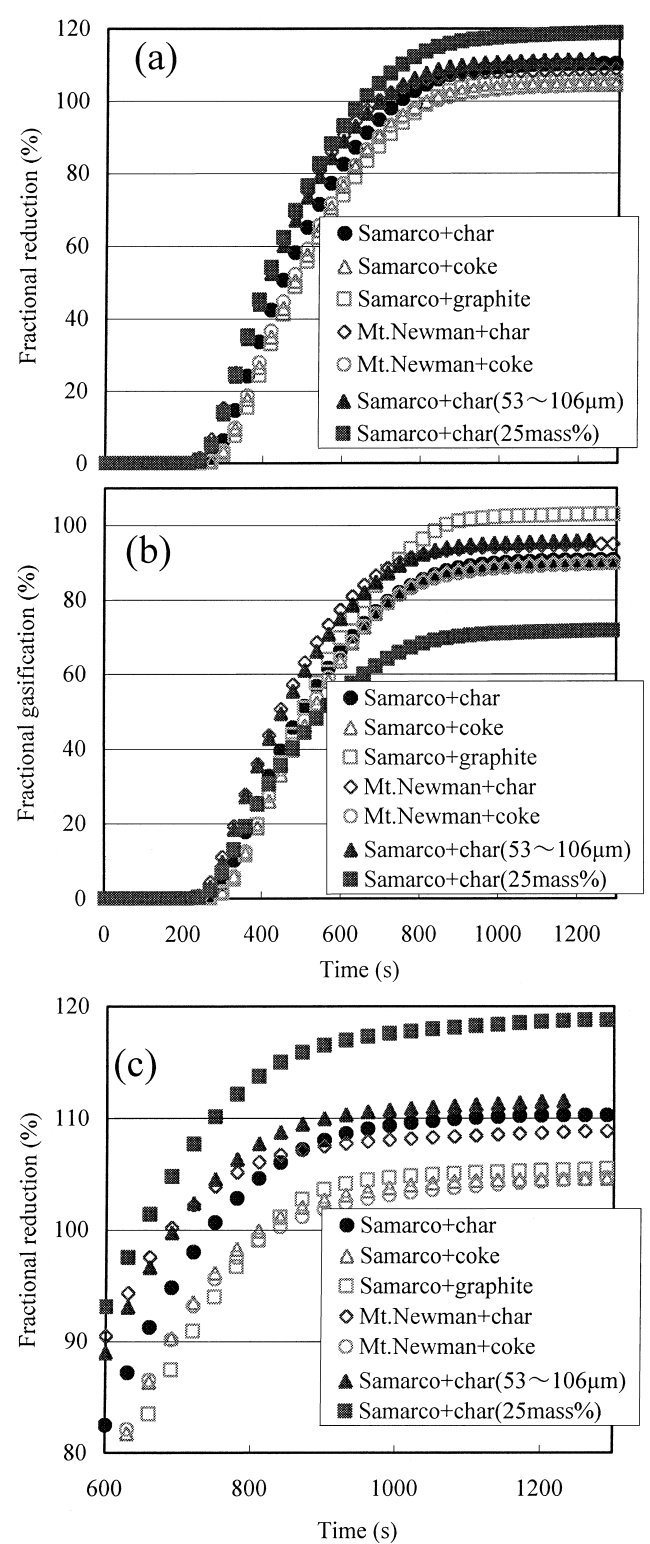

Fig. 1. (a) Reduction degree curves at $1250^{\circ} \mathrm{C}$ and (b) gasification degree curves at $1250^{\circ} \mathrm{C}$ calculated from the time variation in the contents of $\mathrm{CO}$ and $\mathrm{CO}_{2}$ in the outlet gas and (c) is an enlarged figure of (a) in the later stage. nor core is formed. Although, at $1250^{\circ} \mathrm{C}$, some difference starts to be observed between the exterior part and the central part, no clear void is formed, namely neither the shell nor the core is formed. At $1300^{\circ} \mathrm{C}$, a few small separate voids start to form inside the pellet in spite of being not yet pieced together into one. Increasing the temperature up to $1350^{\circ} \mathrm{C}$, the voids pieced together into one large void as observed in Fig. 2(d) and the core part is attached to the inside wall of the shell. In the outer part of the shell, the size of the reduced iron particles are almost the same as that of the original iron ore particles, but it gradually increases as the radial position moves towards the center of the pellet. Process forming the morphology of the coalesced particles is supposed as follows. The reactions in the composite pellets start first at the exterior part and gradually propagate towards the center, and they finish first at the exterior part and the reacted part also propagates towards the center. Since the remained amount of carbon in the outer part of the shell is usually less than 1 mass $\%$, which is too low to cause the reduced iron particles to coalesce, the reduced iron particles hardly coalesce and the shape and size of the original spherical pellet is almost maintained forming the shell. The carbon content of the core part is significantly greater than that of the shell part because the core part is held at significantly lower temperature than the shell part, e.g. by about $180 \mathrm{~K}^{9)}$ in the initial period, and is fed with $\mathrm{CO}$ gas from the shell part. The driving force for the reduced iron particles to coalesce is their large surface energy coming from their large specific surface area. As the carbon content approaches the solidus line, the $\mathrm{Fe}-\mathrm{C}$ solid solution approaches the melting point and the diffusivity of $\mathrm{Fe}$ atoms in the solution is reasonably thought to gradually increase. Thus, the reduced iron particles of the core part significantly coalesce. The rate of the coalescence may be affected also by the temperature. As the temperature increases, the coalescence is enhanced. During coalescencing, the original small numerous voids among the particles are pieced together to form a few much larger voids inside the pellet, which voids is seen in Figs. 2(c) and 2(d). The coalesced large particle adheres to the inside wall of the shell due to the partial linkage or form a separate small core.

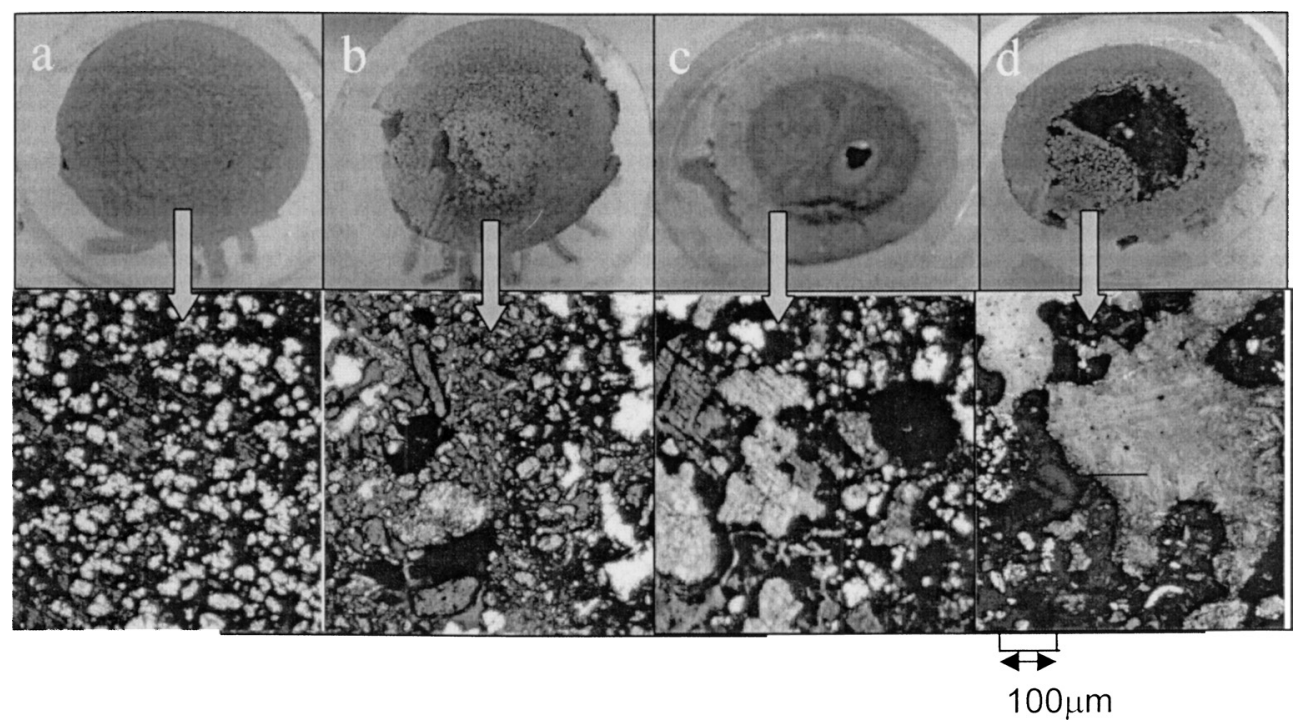

Fig. 2. Microphotographs of the cross sections of reduced iron obtained by heating Samarco ore-coke composite pellets at a: 1200, b: 1250, c: 1300 and d: $1350^{\circ} \mathrm{C}$. 
In the literature, ${ }^{1,2)}$ the reduction of iron oxides, coalescence of reduced iron particles, separation of slag component from reduced iron particles were reported in heating experiments in $\mathrm{N}_{2}$ of composite pellets of magnetite ore with $18.5-22.3$ mass \% carbonaceous material of $17 \mathrm{~mm}$ in diameter. The article described that melting of reduced iron and/or slag can proceed at $1380^{\circ} \mathrm{C}$ or more, but it never does at $1330^{\circ} \mathrm{C}$ or less and the melting starting temperature is within $1330-1380^{\circ} \mathrm{C}$. On the other hand, it was reported $^{7)}$ in the condition of temperature and $50 \% \mathrm{~N}_{2}-$ $\mathrm{CO}-\mathrm{CO}_{2}$ gas mixtures which simulated blast furnace using carbon-composite iron-ore briquette that the reduction of wustite started from $750^{\circ} \mathrm{C}$ and finished at $1100^{\circ} \mathrm{C}$, reduced iron particles were carburized partially at $1200^{\circ} \mathrm{C}$ and up to $1 \% \mathrm{C}$ at $1300^{\circ} \mathrm{C}$, started to coalesce at $1300^{\circ} \mathrm{C}$ and wholly melted down at $1380^{\circ} \mathrm{C}$.

\subsection{FeO Content in the Composite Pellets When the Reactions Finished}

As shown in Fig. 1, the final reduction degree exceeded

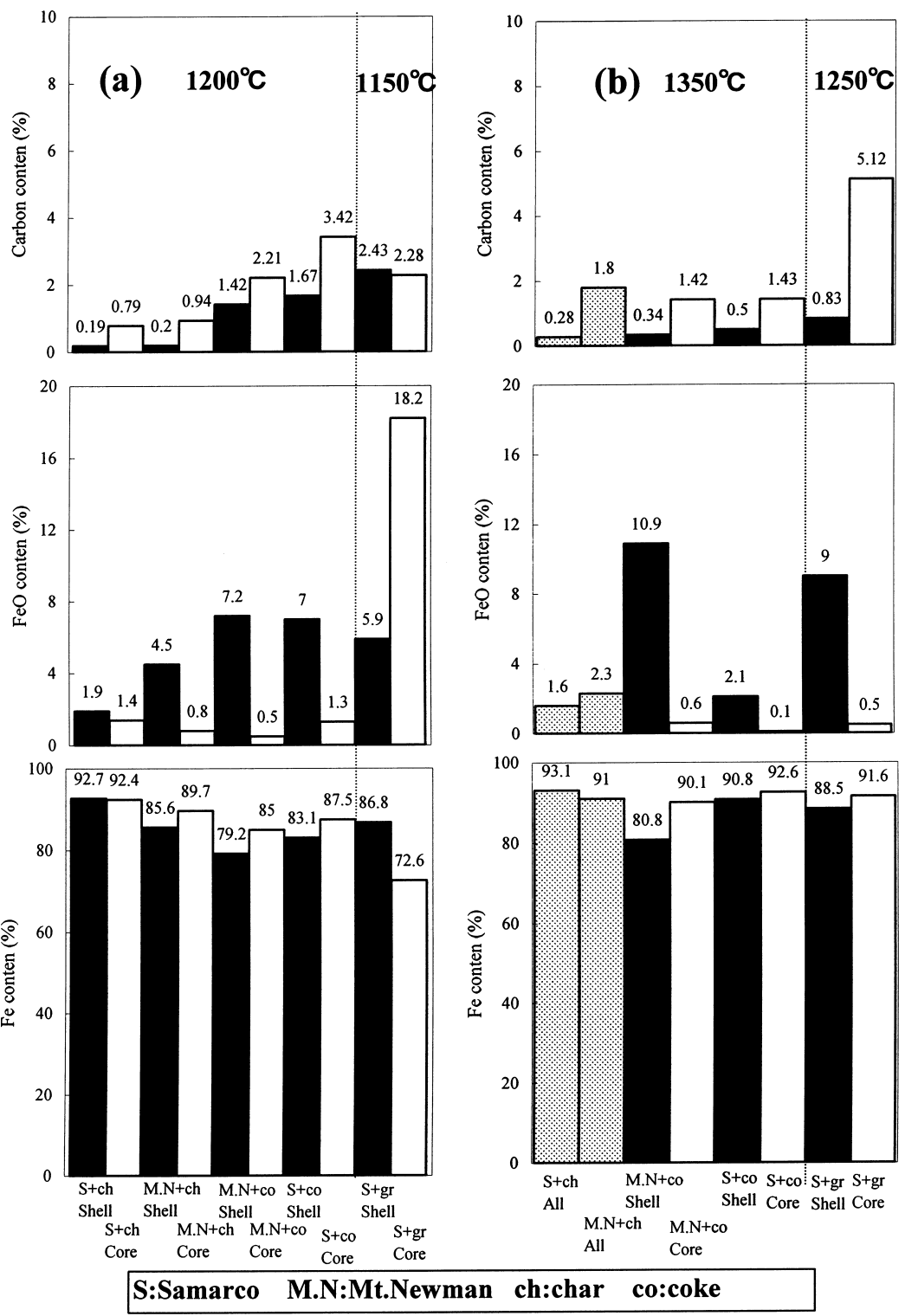

Fig. 3. Relationship between the content of dissolved carbon, the content of divalent iron oxide (FeO), and the content of metallic iron in the shell and core parts of reacted pellets or the whole pellets after the reactions finished. (a) Temperature is $1200^{\circ} \mathrm{C}$ except $1150^{\circ} \mathrm{C}$ for Samarco ore-graphite. The heating time is $15 \mathrm{~min}$. (b) Temperature is $1350^{\circ} \mathrm{C}$ except $1250^{\circ} \mathrm{C}$ for Samarco ore-graphite. The heating time is $11 \mathrm{~min}$.
$100 \%$ probably due to the remained water even in dried composite pellets. The final reduction degrees, which were calculated from the composition and flow rate of the outlet gas, are not so correct. In order to correctly evaluate the final reduction degree, therefore, the shell parts and core parts of reduced iron when the reactions just finished were chemically analyzed for metallic iron and divalent iron, i.e. FeO. The relationships between the carbon content, FeO content and metallic iron content at relatively low temperatures, i.e. $1200^{\circ} \mathrm{C}$ for the coal char or coke bearing pellets and $1150^{\circ} \mathrm{C}$ for the graphite bearing pellet, and at relatively high temperatures, i.e. $1350^{\circ} \mathrm{C}$ for the former and $1250^{\circ} \mathrm{C}$ for the latter, are shown in Figs. 3(a) and 3(b), respectively. Although the reactions of the composite pellets seemed to be almost completed, several percentages of $\mathrm{FeO}$ remain in the pellets. For the composite pellets reacted except the graphite bearing pellet reacted at $1150^{\circ} \mathrm{C}$, the carbon content in the core part is greater than that in the shell part while the $\mathrm{FeO}$ content in the core is much lower than that in the shell. Comparing the carbon content between the shell 
part and the core part in each composite pellet, it is almost general that the final-stage reduction of wustite seems to be made by the carburized carbon in reduced iron. But, comparing the carbon contents of the core part for the various kinds of the composite pellets, it is not necessarily true that the more the carbon content the lower the $\mathrm{FeO}$ content. Nevertheless, a weak tendency for the FeO content to decrease with increasing the carbon content seems to be present. The carbon content of the shell part is also the case. With regards to the influence of the heating temperature, the carbon content in the pellet reacted at $1350^{\circ} \mathrm{C}$ is lower than that in the pellet reacted at $1200^{\circ} \mathrm{C}$, but the content of metallic Fe for the pellets reacted at $1350^{\circ} \mathrm{C}$ is greater than that at $1200^{\circ} \mathrm{C}$ and the $\mathrm{FeO}$ content of the former is not necessarily higher than the $\mathrm{FeO}$ content of the latter.

\section{Considerations}

Based on the present authors' previous studies, ${ }^{8,10-12)}$ the characteristics of the reactions in the composite pellets heated at elevated temperatures are concluded as follows.

1) The overall reduction rate in the composite pellets containing the coke or graphite, which gasification rates are very slow compared to the coal char, is not slower than the rate in the composite pellets containing the coal char. This result means that the overall reduction rate is not controlled by the gasification rate. Furthermore, the carbon content of the former composite pellets is much greater than that of the latter ones as summarized in Fig. 4. This means that the carburization of reduced iron is mainly conducted by the direct carburization reaction, i.e.

$$
\mathrm{C}(\mathrm{s})=[\mathrm{C}] \text {. }
$$

through direct contact of reduced iron with carbon in carbonaceous materials.

2) The coalescence of the reduced iron particles progresses at each temperature provided that the carbon content of the particles approaches the carbon content of the solidus line of $\mathrm{Fe}-\mathrm{C}$ binary system. The rate of the coalescence for the particles increases with increasing temperature.

3) When the reduced iron particles coalesce with neighboring particles, the particles of the coke and coal char are easily liberated from the contact state with the reduced iron particles and released into the void formed in composite pellets.

4) The gangue materials segregated on the surface of iron ore particles is reported ${ }^{5}$ to prevent the reduced iron particles being carburized. But, in this study, any significant prevention was not observed with the finely pulverized iron ore particles of Mt. Newman to less than $45 \mu \mathrm{m}$. The fact observed in this study was that some gangue materials were taken into the coalesced reduced iron particles along with some round voids taken into for the Mt. Newman ore bearing composite pellets. For the Samarco ore bearing composite pellets, the phenomenon was never observed.

5) The carburization of reduced iron when the reactions just finished in nitrogen atmosphere can be achieved up to near the solidus line. As shown in Fig. 4, howev-

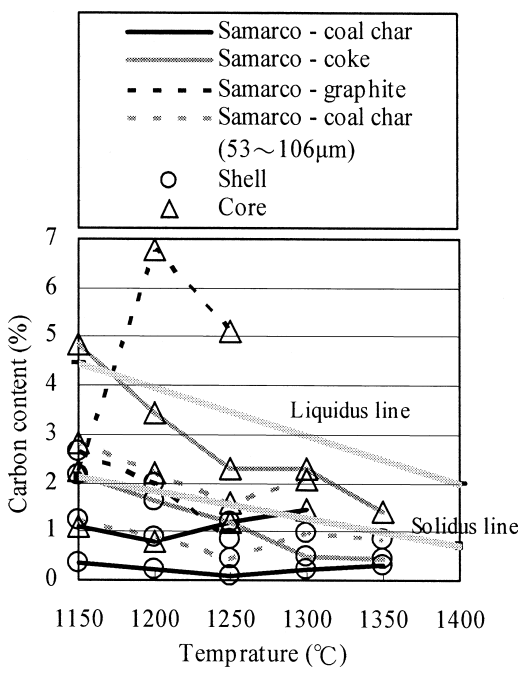

Fig. 4. Variation of the carbon content of the shell part and core part of the composite pellets reacted until the reactions finished with the heating temperature. This figure is summarized from the authors' previous study. ${ }^{8}$

er, the reduced iron carburizing ability of the carbonaceous materials may be strongly dependent on their level of crystalline state as follows; graphite achieved the carburization up to the solidus line as excellent carburizing material, coke achieved it up to near the line and the coal char achieved it only to less than $0.5 \mathrm{mass} \%$ as the poorest carburizing material of the three. But by using a larger size range, i.e. 53-106 $\mu \mathrm{m}$, of the coal char, the ability to carburize reduced iron was significantly improved. The amount of ash contained in the carbonaceous materials may not affect the carburization rate.

In the previous study, ${ }^{2)}$ the gaseous carburization by Reaction (6)

$$
2 \mathrm{CO}=[\mathrm{C}]+\mathrm{CO}_{2}
$$

is claimed to be the main carburizing reaction even at temperatures more than $1000^{\circ} \mathrm{C}$. On the other hand, there is the study ${ }^{13)}$ insisting that the carburization rate by Reaction (6) gradually decreases with increasing temperature provided that the temperature exceeds $1000^{\circ} \mathrm{C}$. In spite of the very slow gasification rate of graphite, the shell part of the reduced iron of Samarco ore-graphite composite pellets melted even at $1250^{\circ} \mathrm{C} .{ }^{11)}$ Namely, the carburization proceeded to enough extent to melt the reduced iron by the mechanism due to the direct carburization.

\subsection{Relationship between Overall Reduction Rate and Gasification Rate}

Viewing deeply the reduction curves and gasification curves shown in Figs. 1 (a) and 1(b) and the content of remained $\mathrm{FeO}$ shown in Fig. 3, the overall reduction rate in the composite pellets does not seem to be controlled by the gasification reaction. The coke or graphite bearing composite pellets are reduced at a comparable rate to or a rather faster rate than the coal char bearing composite pellets although the former two carbonaceous materials are much more slowly gasified than the latter one. In addition to the fact, the carbon contents of reduced iron from the graphite or coke bearing composite pellets are much greater than 
those from the coal char bearing composite pellets as shown in Fig. 4. The formation of $\mathrm{CO}$ gas in the former composite pellets seems to mainly depend on the following direct reactions

$$
\begin{gathered}
3 \mathrm{Fe}_{2} \mathrm{O}_{3}+\mathrm{C}=2 \mathrm{Fe}_{3} \mathrm{O}_{4}+\mathrm{CO} \\
\mathrm{Fe}_{3} \mathrm{O}_{4}+\mathrm{C}=3 \mathrm{FeO}+\mathrm{CO} . \\
\mathrm{FeO}+\mathrm{C}=\mathrm{Fe}+\mathrm{CO} \ldots \ldots \\
\mathrm{FeO}+[\mathrm{C}]=\mathrm{Fe}+\mathrm{CO} \ldots \ldots
\end{gathered}
$$

The formation of $\mathrm{CO}$ gas in the coal char bearing composite pellets, on the contrary, may be the gasification reaction

$$
\mathrm{C}+\mathrm{CO}_{2}=2 \mathrm{CO} \text {. }
$$

The formation of $\mathrm{CO}_{2}$ gas may be formed by the indirect reduction reactions

$$
\begin{gathered}
3 \mathrm{Fe}_{2} \mathrm{O}_{3}+\mathrm{CO}=2 \mathrm{Fe}_{3} \mathrm{O}_{4}+\mathrm{CO}_{2} \\
\mathrm{Fe}_{3} \mathrm{O}_{4}+\mathrm{CO}=3 \mathrm{FeO}+\mathrm{CO}_{2} \ldots \\
\mathrm{FeO}+\mathrm{CO}=\mathrm{Fe}+\mathrm{CO}_{2} \ldots \ldots
\end{gathered}
$$

Whether $\mathrm{CO}$ is formed by the direct reactions of Reactions (7)-(10) or the gasification reactions of Reaction (11) shall be figured out in the composition of the outlet gas. The ratio of $\mathrm{CO}_{2} \% /\left(\mathrm{CO} \%+\mathrm{CO}_{2} \%\right)$ in the outlet gas, which were calculated from their concentrations measured by infra-red analysis, is shown in Fig. 5. The values for the ratio in the time range from 250 to $900 \mathrm{~s}$, which values are of an enough precision because the concentrations of $\mathrm{CO}$ and $\mathrm{CO}_{2}$ in $\mathrm{N}_{2}$ were sufficiently high to be measured by infrared gas analyzer, are divided into the initial period during which the ratio rapidly increases up to the maximum around 2.5 and rapidly drops to less than about 0.2 , and the later period during which the ratio monotonously decreases slowly from about 0.2 to less than 0.1 . Considering the result shown in Fig. 5 comparing to that in Fig. 1, the initial period and the later period correspond to reduction from hematite to wustite and reduction from wustite to metallic iron. In the initial period, the ratio starts to drop at relatively longer times with the composite pellets of Samarco+graphite, Mt. Newman+coke and Samarco+coke (abbreviated as group 1) comparing to the composite pellets of Samarco+char (25\%), Samarco+char and Mt. Newman + char (abbreviated as group 2). In the later period, the ratio for the group 1 is significantly smaller than the ratio for the group 2. The coal char composite pellets, which showed much faster gasification rate ${ }^{8,14)}$ and much lower carbon content ${ }^{8)}$ than the coke and graphite, show the greatest ratio, namely the highest contribution of the indirect reduction, of the three carbonaceous materials during the reduction step from wustite to metallic iron. On the contrary, the coke or graphite composite pellets show much slower gasification rate ${ }^{8,14)}$ and much higher content of carburized carbon, ${ }^{8)}$ and much lower contribution of indirect reduction. Furthermore, the fact that the overall reduction rate of iron ore is not necessarily decided by the contribution of the direct reactions, i.e. Reactions (5) and (7)-(10), also suggest that the Reaction (5) and Reaction (11) are not independent of each other, but they are strongly correlated with each other. The fast progress of Reaction (11) may result in depressing the progress of Reaction (5). At the con-

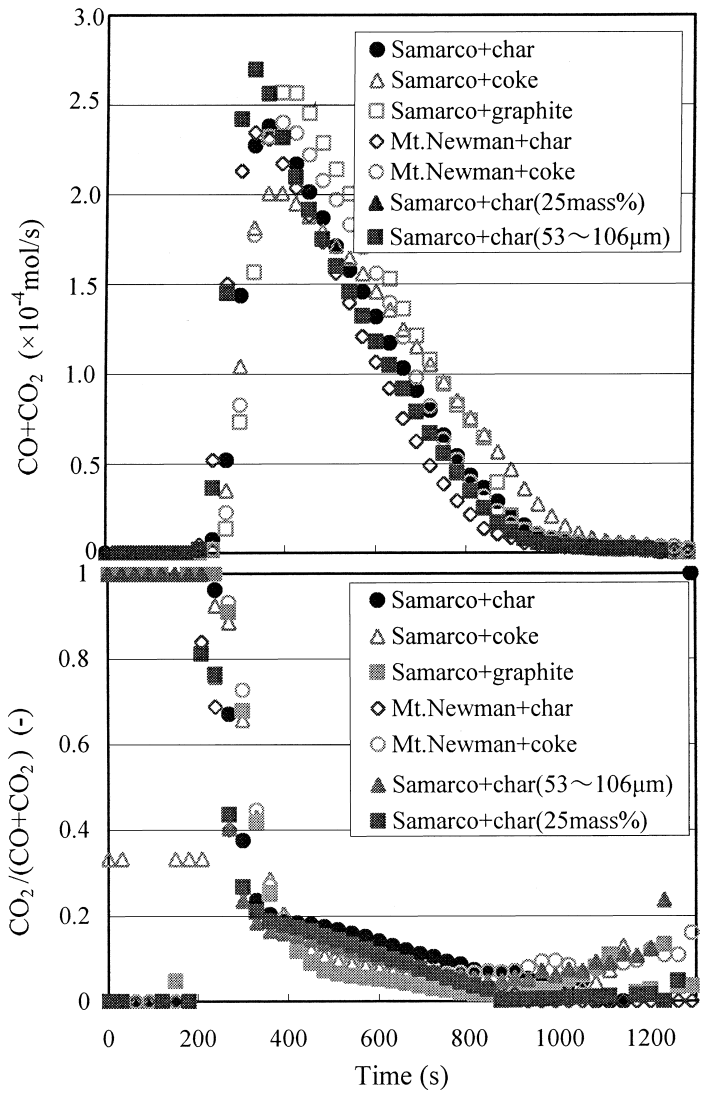

Fig. 5. Variations in the evolving rates of $\mathrm{CO}$ and $\mathrm{CO}_{2}$, and $\mathrm{CO}_{2} /\left(\mathrm{CO}+\mathrm{CO}_{2}\right)$ ratio with the heating time at $1250^{\circ} \mathrm{C}$.

tact points between the reduced iron particles and the carbon particles, Reaction (11) is to be enhanced due to the catalytic effect of iron ${ }^{14)}$ prior to the free surface of the carbon particles and Reaction (5) may be depressed because carbon atoms at the contact points are preferentially consumed by the Reaction (11).

\subsection{Coalescence of the Reduced Iron Particles}

According to the observation of the cross sections shown in Fig. 2, the reduced iron in the core part was generally carburized to a much higher level than the shell parts. As shown in the previous study, ${ }^{9)}$ in which the experimental conditions were very near in this study, the temperature at the center of $18 \mathrm{~mm}$ composite pellets was usually lower than that on the surface initially by at least $180 \mathrm{~K}$ when heated at elevated temperatures and then the temperature at the center gradually approached the temperature at the surface as the reactions progressed. For that reason, the reactions of a composite pellet starts at the shell part and the $\mathrm{CO}$ gas formed there by the gasification reaction diffuses not only out of the pellet and but also inward the pellet in the initial period. Since, in the core part, the reactions progressed at significantly lower temperatures than the shell part and the core part of the pellet is supplied with $\mathrm{CO}$ gas from the shell part in the initial period, the carbon content of the core part in the pellet at the time when the reactions just finish is much higher than that of the shell part as shown in Fig. 4. With regards to the composite pellets bearing the graphite or the coke, the mechanism by which the carbon content at the core is higher than that at the shell is schematically shown in Fig. 6. The carbon content locates 


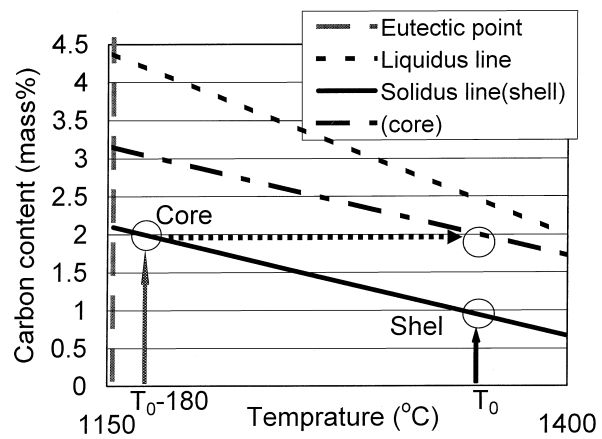

Fig. 6. Schematic representation of the higher content of carbon at the core than at the shell due to the lower temperature at the core than at the shell.

in the two-phase equilibrium zone of $\gamma$-Fe and iron melt between the solidus line and the liquidus line of $\mathrm{Fe}-\mathrm{C}$ binary system phase diagram and decreases with increasing temperature.

With regards to the size and shape of reduced iron particles, the reduced iron particles near the exterior surface of reacted composite pellets almost hold the shape and size of original iron ore particles. However, the size of iron particles gradually grows with inward moving the observation position from the exterior part to the interior of the shell part. That is, the tendency for the reduced iron particles to coalesce is gradually strengthened as the carbon content approaches the solidus line. This coalescing phenomenon was observed at $1150^{\circ} \mathrm{C}$ with graphite bearing composite pellets and at $1200^{\circ} \mathrm{C}$ or more with coal char and coke bearing composite pellets. Consequently, without exception, the reduced iron particles always coalesce before the particles melt down by being carburized up to near and beyond the solidus line. The rate of the coalescence is expected to gradually increase not only when the temperature is increased but also the melting temperature is lowered by the increased content of carburized carbon. The reason would be the accelerated diffusion rate of iron atoms as the state approaches the solidus line by the carburization or temperature rise.

\subsection{Detaching of Carbonaceous Material Particles from Reduced Iron Particles}

When the reacted composite pellets were drilled with a small hole, a certain amount of carbonaceous material particles were observed to fall down from inside the void space. These carbon particles are thought to be excluded from among the reduced iron particles into the void as the particles coalesce.

The detached particles of the graphite have never been observed while the detached particles of the coke were most often observed of the three carbonaceous materials, and the coal char particles were in the intermediate order among them. Considering the experimental results in detail, the liberation of free carbon particles seems to be affected by the amount of ash in the carbonaceous materials, namely free particles were most often observed for the coke containing about 11 mass $\%$ ash $>$ observed in some cases for coal char containing 2.7 mass $\%$ ash $>$ never observed for graphite containing 0.27 mass $\%$ ash. Namely, the ash in carbonaceous materials particles can weaken a certain ad- hering force of the particles to reduced iron particles. In this study, the void was formed inside the composite pellets whenever the coalescence of the reduced iron particles occurred at $1300^{\circ} \mathrm{C}$ or more. But in literature, no observation of the void formation was also reported although the coalescence of the reduced iron and the liberation of free carbon particles occurred. ${ }^{2)}$

\subsection{Influence of Gangue Materials in Iron Ore on the Coalescence of Iron Ore Particles}

Based on the experimental results conducted by using the coal char, the influence of the kind of iron ore on the carburization and coalescence of reduced iron is discussed. Some difference was observed between the morphology of coalesced reduced iron particles from Samarco ore and that from Mt. Newman ore. In the coalesced large particles in the Samarco ore bearing composite pellets, void space and gangue material particles were never observed. But, in the coalesced reduced iron particles from Mt. Newman ore, some round spaces as large as several times the reduced iron particles' and small gangue materials were observed to be brought into, which spaces were not observed due to being extruded out of the coalesced granules in a further proceeded step. Taking in a round space and gangue materials into coalesced granules may be caused by a mechanism which is attributable to the location of the gangue materials on the exterior surface of the iron ore particles. In the literature, ${ }^{5)}$ it was reported that the lower limit temperature required for separating slag from metallic iron is raised to a higher temperature by the segregated presence of gangue materials on the exterior surface of iron ore particles.

\subsection{Why the Reduced Iron Particles Do Not Melt until Heated at Far Higher Than the Eutectic Tempera- ture?}

As shown in the previous study, ${ }^{8)}$ the carbon content for the shell parts of reduced iron from the coke composite Samarco ore or Mt. Newman ore pellets at 1200 and $1250^{\circ} \mathrm{C}$, until the reactions just finished, locates near the solidus line. Considering the results shown in Fig. 5, the content of remained carbon should be in the order of the coal char $>$ coke $>$ graphite. Nevertheless, the carbon content of the reduced iron for the coal char is much less than the coke and graphite as shown in Fig. 4. Furthermore, some amounts of un-reacted coke particles remained in the composite pellets after the reactions finished because some coke particles were observed to fall down from the void when the reacted pellets were drilled with a small hole. Thus, it is concluded that a significant amount of carbon always remained even after the reactions finished. Nevertheless, the reduced iron particles are not carburized to the enough level to melt down the reduced iron. At $1350^{\circ} \mathrm{C}$, the carbon content of the whole reduced iron is a little lower than the solidus line except the graphite bearing composite pellets. Generally considering, the rate of reactions should increase exponentially with temperature. The opposed results to the theory was obtained in this study. That is, there should be a certain reaction step controlling the carburization rate. As can be realized from the experimental results described above, heating the composite pellets at more than $1350^{\circ} \mathrm{C}$ is needed to melt the reduced 
iron. The carbon content of the shell parts seems to be difficult to exceed the solidus line. The carbon contents of the core parts exceeded the solidus line except the results with the coal char bearing composite pellets heated at less than $1300^{\circ} \mathrm{C}$. Since the mass fraction of reduced iron in the core parts is significantly less than that in the shell parts, the whole reduced iron pellet is hardly melted at the temperature. The reason why the carbon contents usually do not exceed the solidus line may be attributed to that the carbonaceous material particles are detached from the reduced iron particles when the reduced iron particles coalesce. When the reduced iron particles melt, they can not avoid the coalescing step. The coalescence of the reduced iron particles always accompanies a change in the shape of the reduced iron particles. During the coalescence, the particles of the carbonaceous materials, which had been in a good contact state with the reduced iron particles, very easily lose it. The detached free carbon particles can not carburize the reduced iron particles due to the poor contact state. In order to force the reduced iron to be carburized beyond the solidus line, it is needed that a sufficiently good contact state is recovered to promote the carburization, but it can not be attained until the composite pellets are heated to more than $1350^{\circ} \mathrm{C}$ ore more, where ash and gangue materials are expected to be softened and melted. To attain the state, it is essential to heat the composite pellets up to $1350^{\circ} \mathrm{C}$ or more depending on the composition and segregation of the gangue materials and ashes. The presence of the phenomenon of the liberation of carbon particles during heating composite pellets is also reported in literature. ${ }^{2)}$

On the contrary, it is reported by Meng et al. ${ }^{11)}$ that composite pellets of electrolytic iron particles of less than $45 \mu \mathrm{m}$ containing the graphite or coal char of less than $45 \mu \mathrm{m}$ melted pretty fast from the surface as droplets even at $1200^{\circ} \mathrm{C}$ or $1250^{\circ} \mathrm{C}$, respectively. The electrolytic iron particles, which were prepared by mechanically pulverizing electrolytic iron plates about $1 \mathrm{~cm}$ thick, have only very small specific surface area and very small surface energy compared to the reduced iron from iron ore particles due to the much smaller specific surface area. For the small surface energy, the particles of the electrolytic iron have relatively very small driving force for the coalescence and could maintain a good contact state with the coal char or graphite.

\section{Conclusions}

Iron ore-carbonaceous materials composite pellets were heated at elevated temperatures. After the reacted pellets were separated in the shell part and the core part, the individuals were pulverized, cleaned repeatedly in fresh ethanol under ultrasonic vibration and were analyzed for carbon by combustion method. This method permitted the measurements for the content of carbon dissolved in reduced iron with an enough precision. Discussing about the carburization and the coalescence of reduced iron particles on the basis of the results obtained in the previous study, ${ }^{8)}$ the following conclusions are obtained.

(1) The reduction of iron ore in the composite pellets are not controlled by the gasification reaction of carbon, but the dissolved carbon by the direct carburization reaction can compensate the deficient in carbon monoxide due to the slow gasification reaction.

(2) Considering each reacted pellet, the carbon content of the core part is always greater than that of the shell part and the $\mathrm{FeO}$ content of the former is lower than the latter except the graphite bearing pellet reacted at $1150^{\circ} \mathrm{C}$. The difference in the carbon content seems to be mainly caused by the temperature difference, the core part being always lower than in the shell part due to the endothermic reactions. The difference in the $\mathrm{FeO}$ content seems to be mainly caused by the difference in the carbon content. Diffusion of $\mathrm{CO}$ gas from the shell part to the core part in the initial period may contribute the differentiation of the carbon content and $\mathrm{FeO}$ content.

(3) The carbon content in the coke or graphite bearing composite pellets can easily approach up to near the solidus line of $\mathrm{Fe}-\mathrm{C}$ binary system by the direct carburization mechanism. At the carbon content, however, the reduced iron particles coalesced into much larger granules. The driving force for the coalescence of the reduced iron particles is presumed to be the large surface energy of reduced iron due to the large specific surface area.

(4) During the coalescence of reduced iron particles, the particles of coke which had been in contact with the reduced iron particles are easily detached away and the detachment seems to be enhanced by the high level of ash in carbonaceous materials. The particles of graphite, however, can keep good contact state with reduced iron even during the coalescence probably due to the very low level of ash amount.

(5) Due to the coalescence of reduced iron particles and the detachment of carbon particles, the carbon contents of the shell and core parts of reduced iron decreases with increasing temperature in the temperature range of $1200-1350^{\circ} \mathrm{C}$ for coke, and $1150-1250^{\circ} \mathrm{C}$ for graphite. And the carburization of reduced iron particles is limited up to the solidus line.

(6) Due to the lower temperature of the core part, the carbon content of the core for the coke or graphite bearing composite pellets is in the two-phase equilibrium range of $\gamma$-iron and iron melt and decreases with temperature in parallel to the solidus or liquidus lines.

(7) Graphite particles seem to have been in good contact with reduced iron particles in spite of the coalescence of the reduced iron particles probably due to the crystallite character. The corresponding carbon content in graphite bearing composite pellets is greater than the liquidus line from the eutectic point to $1250^{\circ} \mathrm{C}$.

(8) The reason why the reduced iron in iron ore-coal char or coke composite pellets does not melt until heated above $1350^{\circ} \mathrm{C}$ can be explained by the coalescence of the reduced iron particles, which is caused by the driving force of the large surface energy of reduced iron.

\section{Acknowledgement}

Part of this study is supported by a fund for the research promotion of science and technology of The Ministry of Education, Culture, Sports, Science and Technology. The authors would like to express our sincere appreciation for the support. 
ISIJ International, Vol. 44 (2004), No. 12

\section{REFERENCES}

1) T. Matsumura, Y. Takenaka, M. Shimizu, T. Negami, I. Kobayashi and A. Uragami: Tetsu-to-Hagané, 84 (1998), 405.

2) T. Matsumura, Y. Takenaka and M. Shimizu: Tetsu-to-Hagané, 85 (1999), 652.

3) S. Inaba: Tetsu-to-Hagané, 87 (2001), 221.

4) C. Kamijo, M. Hoshi, T. Kawaguchi, H. Yamaoka and Y. Kamei: ISIJ Int., 41 (2001), S13.

5) Y. Sawa, T. Yamamoto, K. Takeda and H. Itaya: ISIJ Int., 41 (2001), S17.

6) Y. Matsui, M. Sawayama, A. Kasai, Y. Yamagata and F. Noma: ISIJ
Int., 43 (2003), 1904

7) A. Kasai, M. Naito, Y. Matsui and Y. Yamagata: Tetsu-to-Hagané, 89 (2003), 1212.

8) Y. Iguchi and S. Endo: ISIJ Int., 44 (2004), 1991.

9) Y. Iguchi and R. Kamei: Tetsu-to-Hagané, 85 (1999), 439.

10) H. Sakamoto, Y. Iguchi and S. Hayashi: Tetsu-to-Hagané, 83 (1997), 175.

11) F. Meng, Y. Iguchi and M. Kojima: Tetsu-to-Hagané, 87 (2001), 585.

12) Y. Iguchi and Y. Takada: ISIJ Int., 44 (2004), 673.

13) X. Zhang, R. Takahashi, T. Akiyama and J. Yagi: Tetsu-to-Hagané, 83 (1997), 299

14) F. Meng, Y. Iguchi and S. Hayashi: Tetsu-to-Hagané, 88 (2002), 479. 